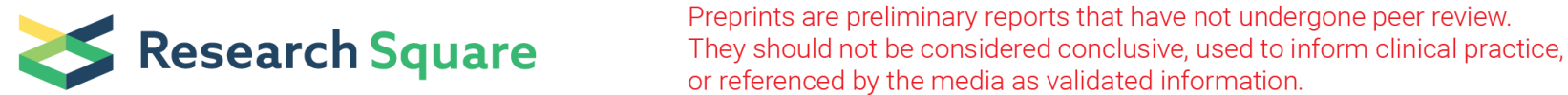

\section{Application of PCT, CRP and WBC levels in the differential diagnosis of acute bacterial, viral, and mycoplasmal respiratory tract infections}

\section{Yang Li}

Children's Hospital of Soochow University

Lanfang Min

Children's Hospital of Soochow University

Xin Zhang (D2937558984@qq.com)

Children's Hospital of Soochow University

\section{Research Article}

Keywords: Children, ARTI, Inflammatory indicators, Bacterial infection, Differential diagnosis, PCT

Posted Date: September 17th, 2021

DOI: https://doi.org/10.21203/rs.3.rs-898490/v1

License: (c) This work is licensed under a Creative Commons Attribution 4.0 International License.

Read Full License 


\section{Abstract \\ Background}

There is a lack of studies comparing PCT, CRP and WBC levels in the differential diagnosis of acute bacterial, viral, and mycoplasmal respiratory infections. It is necessary to explore the correlation between above markers and different types of ARTI.

\section{Methods}

108 children with confirmed bacterial infection were regarded as group A, 116 children with virus infection were regarded as group $B$, and 122 children with mycoplasma infection were regarded as group $C$. The levels of PCT, CRP and WBC of the three groups were detected and compared.

\section{Results}

The levels of PCT, CRP and WBC in group A were significantly higher than those in groups $\mathrm{B}$ and $\mathrm{C}(\mathrm{P}<$ 0.05). The positive rate of combined detection of PCT, CRP and WBC was significantly higher than that of single detection. There was no significant difference of PCT, CRP and WBC levels between the group of Gram-positive bacteria infection and Gram-negative bacteria infection $(P>0.05)$. ROC curve results showed that the AUC of PCT, CRP and WBC for the diagnosis of bacterial respiratory infections were 0.65 , 0.55 , and 0.58 , respectively.

\section{Conclusions}

PCT, CRP and WBC can be used as effective indicators for the identification of acute bacterial or nobacterial infections in children. The levels of PCT and CRP have higher differential diagnostic value than that of WBC in infection, and the combined examination of the three is more valuable in clinic.

\section{Background}

Pneumonia caused by the acute respiratory tract infections (ARTI) in children has acute onset, rapid development and high mortality. It is the disease with the highest hospitalization rate and mortality of children under 5 years old ${ }^{[1]}$. Studies have found that ARTI is related to bacteria, viruses and mycoplasma, among which viral infection is the most common, accounting for about $90 \%{ }^{[2]}$. However, the early symptoms of children with different types of infection were fever, cough, nasal congestion, runny nose and so on. The specificity of these clinical manifestations is low, which is not conducive to clinical differential diagnosis and treatment. Failure to timely and accurately determine the type of infection leads to increased unnecessary antibiotic exposure and possible antibiotic resistance ${ }^{[3]}$. Therefore, it is 
very important to find an accurate and valid method for the differential diagnosis of ARTI. White blood cell (WBC) has been widely used in the diagnosis of infectious diseases. In recent years, inflammatory indicators such as Procalcitonin (PCT) and C-reactive protein (CRP) have received more and more attention in the field of differential diagnosis of ARTI ${ }^{[4-5]}$. PCT and CRP have a good correlation with disease activity, and can be a good indication of the type of infection ${ }^{[6-8]}$. Although there are some studies on above indicators as infection markers, the comparative analysis of PCT, CRP and WBC among patients with bacterial, viral and mycoplasma ARTI is rare.

Herein, the levels of PCT, CRP and WBC of children with different types of ARTI in Children's Hospital of Soochow University from February 2020 to March 2021 were detected. This study is to analyze the correlation between the type of ARTI and the level of PCT, CRP and WBC. So as to provide reference for the auxiliary differential diagnosis and accurate medication guidance of children with ARTI.

\section{Methods}

\section{General information}

358 children with ARTI were included in the study who were hospitalized in the Children's Hospital of Soochow University from March 2020 to February 2021. 108 children of bacterial infection were treated as group $A, 61$ males and 47 females, age $(2.84 \pm 3.30)$ years old. 116 children with viral infection were treated as group $B, 54$ males and 62 females, age $(4.08 \pm 3.28)$ years old. 122 children with mycoplasma infection were treated as group $C, 54$ males and 68 females, age $(4.04 \pm 3.14)$ years old. There was no significant difference between the sex of three groups $(P>0.05)$.

\section{Inclusion criteria}

All children with ARTI have typical clinical symptoms, and the diagnostic criteria are mainly based on the apractical pediatrics $\square^{[9]}$ by Zhu Futang; The pathogenic virus and IgM antibody of Mycoplasma were detected by peripheral blood, and bacteria were detected by sputum culture; No antibiotics, hormones, etc. were taken before the samples were collected.

\section{Specimen collection and testing}

$6 \mathrm{~mL}$ elbow venous blood was collected and injected into the coagulant tube and the anticoagulant tube containing Ethylene Diamine Tetraacetic Acid. The plasma in the coagulant tube was used to detect PCT, and the whole blood in the anticoagulant tube was used to detect CRP and WBC. The value of PCT above $0.5 \mathrm{ng} / \mathrm{mL}$ was considered positive, the value of CRP more than $8 \mathrm{mg} / \mathrm{L}$ was determined positive, and the value of WBC above $10^{*} 10^{9} / \mathrm{L}$ was considered positive.

\section{Statistical analysis}

The statistical software of SPSS 20.0 was used for data analysis. The measurement data were expressed by mean and standard deviation $(\nabla x \pm s)$, the comparison among groups was tested by $t$ test; The count 
data were expressed by rate or composition ratio (\%), and the comparison among groups was tested by $\chi^{2}$ test. Draw Receiver operating characteristic curve (ROC) and calculate the value of area under the curve (AUC). The difference was statistically significant with $P<0.05$.

\section{Results}

\section{Comparison of PCT, CRP and WBC levels among the three groups}

The levels of PCT, CRP and WBC in group A were significantly higher than those in group $B$ and group $C$ $(P<0.05)$. CRP level of group $C$ is slight higher than group $B$. There was no significant difference in the levels of PCT, CRP and WBC between group B and group $C(P>0.05)$. See Table 1 for details.

Table 1

Comparison of PCT, CRP and WBC levels $[\varangle \mathrm{x} \pm \mathrm{s}]$

\begin{tabular}{|lllll|}
\hline Group & $\mathbf{n}$ & $\mathrm{PCT}(\mathrm{ng} / \mathrm{mL})$ & $\mathrm{CRP}(\mathrm{mg} / \mathrm{L})$ & WBC $\left(10^{9} / \mathrm{L}\right)$ \\
\hline $\mathrm{A}$ & 108 & $1.69 \pm 3.23$ & $25.66 \pm 40.25$ & $10.24 \pm 5.38$ \\
\hline $\mathrm{B}$ & 116 & $0.49 \pm 0.86$ & $12.80 \pm 22.27$ & $8.83 \pm 2.94$ \\
\hline $\mathrm{t}$ & 122 & $0.55 \pm 1.21$ & $14.88 \pm 26.04$ & $8.49 \pm 3.54$ \\
\hline$p_{A-B}$ & - & 3.745 & 2.928 & 2.408 \\
\hline$t_{A-C}$ & - & $<0.001$ & 0.004 & 0.017 \\
\hline$p_{A-C}$ & - & 0.001 & 0.018 & 0.005 \\
\hline$t_{B-C}$ & - & 0.464 & 0.659 & 0.810 \\
\hline$p_{B-C}$ & - & 0.643 & 0.510 & 0.419 \\
\hline
\end{tabular}

\section{Comparison of positive rates of PCT, CRP and WBC among the three groups}

The positive rates of PCT and CRP in group A were significantly higher than those in group B and group C. The differences of PCT and CRP levels among the three groups were statistically significant $(P<0.05)$. There was no significant difference in the positive rate of WBC among the three groups $(P>0.05)$. The combined diagnosis of three indicators can significantly improve the positive rate of diagnosis, as shown in Table 2. 
Table 2

Comparison of positive rates of PCT, CRP and WBC [n,\%]

\begin{tabular}{|llllll|}
\hline Group & $\mathbf{n}$ & PCT $(\mathbf{n g} / \mathrm{mL})$ & $\mathrm{CRP}(\mathrm{mg} / \mathrm{L})$ & WBC $\left(10^{9} / \mathrm{L}\right)$ & Combined diagnosis \\
\hline A & 108 & $57(52.78)$ & $55(50.93)$ & $42(38.89)$ & $94(87.04)$ \\
\hline B & 116 & $25(21.55)$ & $43(37.7 .07)$ & $36(31.03)$ & $78(67.24)$ \\
\hline C & 122 & $29(23.77)$ & $42(34.43)$ & $34(27.87)$ & $78(63.93)$ \\
\hline$\chi^{2}$ & - & 31.00 & 12.07 & 3.32 & 17.44 \\
\hline$P$ & - & $<0.001$ & 0.002 & 0.190 & $<0.001$ \\
\hline
\end{tabular}

ROC curve analysis of PCT, CRP and WBC in the diagnosis of bacterial ARTI

ROC curve analysis showed that the areas under the curve of PCT, CRP and WBC were $0.65,0.55$ and 0.58 respectively. See Table 3 and Fig. 1 for details.

Table 3

The efficacy of PCT, CRP and WBC in the diagnosis of bacterial ARTI

\begin{tabular}{|lllllll|}
\hline Index & AUC & $\begin{array}{l}\text { Cut- } \\
\text { off } \\
\begin{array}{l}\text { (95\% Confidence } \\
\text { interval) }\end{array}\end{array}$ & $\begin{array}{l}\text { Specificity } \\
(\%)\end{array}$ & $\begin{array}{l}\text { Sensitivity } \\
(\%)\end{array}$ & $\begin{array}{l}\text { Positive } \\
\text { predictive } \\
\text { value(\%) }\end{array}$ & $\begin{array}{l}\text { Negative } \\
\text { predictive } \\
\text { value (\%) }\end{array}$ \\
\hline PCT & $0.65(0.59-0.71)$ & 0.49 & 74.80 & 56.5 & 50.4 & 79.1 \\
\hline CRP & $0.55(0.48-0.62)$ & 10.63 & 72.3 & 46.3 & 43.1 & 74.8 \\
\hline WBC & $0.58(0.52-0.65)$ & 11.40 & 81.1 & 31.5 & 43.0 & 72.3 \\
\hline
\end{tabular}

\section{Distribution of bacterial respiratory tract infection strains}

The types of bacteria detected in 108 children of bacterial ARTI were as follows, $\mathrm{G}^{+}$bacteria were mainly Streptococcus pneumoniae and Staphylococcus aureus, $\mathrm{G}^{-}$bacteria were mainly Escherichia coli and Haemophilus influenzae. As shown in Table 4. 
Table 4

The distribution of bacterial respiratory tract infection strains

\begin{tabular}{|c|c|c|c|c|c|}
\hline Group & Type & $\mathbf{n}$ & Ratio (\%) & Total & Ratio (\%) \\
\hline \multirow{3}{*}{$\begin{array}{l}\mathrm{G}^{+} \\
\text {bacteria }\end{array}$} & Streptococcus pneumoniae & 33 & 30.56 & \multirow[t]{3}{*}{60} & \multirow[t]{3}{*}{55.56} \\
\hline & Staphylococcus aureus & 26 & 24.07 & & \\
\hline & Streptococcus agalactiae & 1 & 0.93 & & \\
\hline \multirow{9}{*}{$\begin{array}{l}\mathrm{G}^{-} \\
\text {bacteria }\end{array}$} & Escherichia coli & 12 & 11.11 & \multirow[t]{9}{*}{48} & \multirow[t]{9}{*}{44.44} \\
\hline & Haemophilus influenzae & 10 & 9.26 & & \\
\hline & Moraxella catarrhalis & 7 & 6.48 & & \\
\hline & Acinetobacter baumannii & 6 & 5.56 & & \\
\hline & Pseudomonas aeruginosa & 5 & 4.63 & & \\
\hline & klebsiella pneumoniae & 4 & 3.70 & & \\
\hline & Burkholderia & 2 & 1.85 & & \\
\hline & Enterobacter aerogenes & 1 & 0.93 & & \\
\hline & Stenotrophomonas maltophilia & 1 & 0.93 & & \\
\hline
\end{tabular}

Comparison of PCT, CRP and WBC levels and diagnostic positive rate between $\mathrm{G}^{+}$and $\mathrm{G}^{-}$bacterial infection group

There were no significant differences in PCT, CRP, WBC levels and diagnostic positive rates between $\mathrm{G}^{+}$ and $\mathrm{G}^{-}$bacterial infection groups $(P>0.05)$, as shown in Table 5.

Table 5

Comparison of PCT, CRP and WBC levels and diagnostic positive rate between $\mathrm{G}^{+}$and $\mathrm{G}^{-}$bacterial infection group $[\nabla x \pm s] /[n, \%]$

\begin{tabular}{|c|c|c|c|c|c|c|c|c|}
\hline Group & $\mathrm{n}$ & $\begin{array}{l}\text { PCT } \\
\text { (ng/mL }\end{array}$ & & $\begin{array}{l}\text { CRP } \\
(\mathrm{mg} / \mathrm{L})\end{array}$ & & $\begin{array}{l}\text { WBC } \\
\left(10^{9} / \mathrm{L}\right)\end{array}$ & & $\begin{array}{l}\text { Combined } \\
\text { diagnosis }\end{array}$ \\
\hline $\mathrm{G}^{+}$bacteria & 60 & $\begin{array}{l}1.66 \pm \\
3.19\end{array}$ & $34(56.67)$ & $\begin{array}{l}22.37 \pm \\
36.86\end{array}$ & $31(51.67)$ & $\begin{array}{l}9.82 \pm \\
4.00\end{array}$ & $21(35.00)$ & $52(86.67)$ \\
\hline $\begin{array}{l}\mathrm{G}^{-} \\
\text {bacteria }\end{array}$ & 48 & $\begin{array}{l}1.74 \pm \\
3.31\end{array}$ & $23(47.92)$ & $\begin{array}{l}29.76 \pm \\
44.18\end{array}$ & $24(50.00)$ & $\begin{array}{l}10.77 \\
\pm 6.74\end{array}$ & $21(43.75)$ & $40(83.33)$ \\
\hline$t / \chi^{2}$ & - & 0.13 & 0.82 & 0.95 & 0.03 & 0.91 & 0.86 & 0.24 \\
\hline$p$ & - & 0.90 & 0.37 & 0.35 & 0.86 & 0.34 & 0.35 & 0.63 \\
\hline
\end{tabular}




\section{Discussions}

ARTI is the most common infectious disease in children, and has a significant impact on children's health ${ }^{[10]}$. The diagnosis and differential diagnosis of infection types need the support of bacterial culture and serological diagnosis. The process is time-consuming and tedious, and the results can not be fed back to the clinic in time. Experiential medication is a common clinical treatment, and it is also one of the causes of antimicrobial drug abuse and bacterial resistance ${ }^{[11]}$. It is an urgent problem to quickly distinguish the types of infection and guide clinical accurate drug use. WBC count in blood routine is a common method in clinical diagnosis of infection ${ }^{[12]}$. It is easy to operate and the result is fast. However, it is easy to be interfered by external factors, which affects the choice of clinical medication. Both PCT and CRP are acute phase reaction proteins, which can change according to the level of inflammatory factors. The level of PCT in serum increases significantly, when the body is infected with pathogens. The degree of increase is related to the degree of infection ${ }^{[13-14]}$. CRP is a non-specific acute phase reaction protein synthesized by hepatocytes. As an inflammatory marker, it is easy to detect and has high accuracy. It is widely used in the diagnosis of acute infection and the prognosis of patients ${ }^{[15-16]}$. Therefore, on the basis of bacterial culture and serological identification, combined with other inflammatory factors, it is expected to quickly distinguish the types of acute respiratory infection, and provide meaningful data for clinical reference.

The results of this study show that the levels of PCT, CRP and WBC in group A were significantly higher than those in group $\mathrm{B}$ and group $\mathrm{C}(P<0.05)$. It's clear that bacterial infections can lead to elevated levels of above indicators. It is consistent with the relevant research results ${ }^{[17-18]}$. This may be related to the failure of PCT to break down into calcitonin under the action of cytokines during bacterial infection, resulting in the increase of PCT level in blood ${ }^{[19]}$. There was no significant difference in the levels of PCT, CRP and WBC between group $B$ and group $C(P>0.05)$. And these are similar to the normal value. It further suggests the value in the differential diagnosis of bacterial infection. When PCT, CRP or WBC remarkably increased, the possibility of bacterial infection increased significantly. It can guide the clinical early use of broad-spectrum cephalosporins or aminoglycoside antibiotics for treatment, and can achieve ideal therapeutic effect. Then the positive rates of PCT, CRP and WBC among the three groups were compared. The positive rates of PCT and CRP in group A were significantly higher than those in group $\mathrm{B}$ and group $C(P<0.05)$. This result is consistent with the above. There was no significant difference in the positive rate of WBC among the three groups $(P>0.05)$. More importantly, the combined diagnosis of three indicators can significantly improve the positive rate of diagnosis. In agreement with the findings of the present study, a large number of studies showed that combined detection is conducive to the diagnosis of the disease ${ }^{[20-21]}$. This suggests that clinical multi-index joint detection is very important for the diagnosis of disease.

To further analyze the diagnostic efficacy of PCT, CRP and WBC using ROC curve for bacterial ARTI. The result showed that the AUC of PCT, CRP and WBC were $0.65,0.55$ and 0.58 respectively. The sensitivity and AUC of PCT were higher than those of CRP and WBC. It suggested that the diagnostic value of PCT 
and CRP was better than that of WBC in bacterial infection, and WBC is not useful at all. It was consistent with the relevant research studies ${ }^{[22-23]}$. Because the preferred antibiotics for different bacterial infections are not the same, single broad-spectrum antibiotic treatment is difficult to continuously control the development of the disease, so it is necessary to further explore the types of bacterial infections. Among 108 children with bacterial ARTI, there were 60 cases of $\mathrm{G}^{+}$bacteria and 48 cases of $\mathrm{G}^{-}$bacteria.. As shown in Table $4, \mathrm{G}^{+}$bacteria were mainly Streptococcus pneumoniae and Staphylococcus aureus, $\mathrm{G}^{-}$ bacteria were mainly Escherichia coli and Haemophilus influenzae. As we all know, these bacteria are common pathogens of respiratory tract. Children are very vulnerable to infection due to their poor development and low immunity. Next, the levels and diagnostic positive rate of PCT, CRP and WBC between $\mathrm{G}^{+}$and $\mathrm{G}^{-}$bacterial infection group were depth comparative analyzed. As shown in Table 5 , the overall levels of $\mathrm{G}^{-}$bacterial group are slightly higher than that of $\mathrm{G}^{+}$bacterial group. However, there were no significant differences in PCT, CRP, WBC levels and diagnostic positive rates between $\mathrm{G}^{+}$and $\mathrm{G}^{-}$ bacterial infection groups $(P>0.05)$. This result is a little different from that of Tang et al ${ }^{[6]}$, which may be due to insufficient cases included in this study. In the follow-up work, more cases will be considered in order to get more accurate results for clinic.

\section{Conclusions}

According to the above results, PCT, CRP and WBC are helpful to distinguish acute bacterial or nobacterial infections in children to a certain extent, and their levels can prompt clinicians about infection and try to avoid the abuse of antibiotics. The differential diagnosis effect of PCT and CRP is better than that of WBC. The combined diagnosis of PCT, CRP and WBC can significantly improve the positive rate of diagnosis. It is of great significance for the diagnosis and differential diagnosis of infection.

\section{Abbreviations}

Procalcitonin (PCT), C-reactive protein (CRP), White blood cell (WBC), Acute respiratory tract infections (ARTI), Receiver operating characteristic curve (ROC), Area under the curve (AUC).

\section{Declarations}

\section{Acknowledgements}

The investigators would like to thank the members of the investigational teams in all participating hospitals for all the time and efort it takes to carry out this study

\section{Authors' contributions}

YL: Funding acquisition (lead); Methodology (equal); writing-original draft (equal). L-F M: Data curation (equal); Formal analysis (equal); Methodology (equal). XZ: Conceptualization (lead); data curation 
(equal); data curation (equal); formal analysis (equal); validation (equal); writing-original draft (equal); writing-review and editing (lead).

\section{Funding}

The study was supported by grants from the General medical research project of Jiangsu Health Commission (M2020027) and Suzhou Science and Technology Project (SYS2020163).

\section{Availability of data and materials}

The data are available from the corresponding author on reasonable request.

\section{Ethics approval and consent to participate}

This research has been approved by the ethics committee of Children's Hospital of Soochow University. Ethics number is 2021 CS158.

\section{Consent for publication}

The ethical approval and patient information include consent to publish collected data.

\section{Competing interests}

The authors declare that there is no confict of interest.

\section{Author' details}

Yang Li is a technician in charge of Department of clinical laboratory, Children's Hospital of Soochow University, and his e-mail address is 11418092@zju.edu.cn. Lanfang Min is a technician in charge of Department of clinical laboratory, Children's Hospital of Soochow University, and her e-mail address is angle001188@sina.com. Xin Zhang is junior examiner in charge of Department of clinical laboratory, Children's Hospital of Soochow University. She graduated from Chongqing Medical University with a master's degree. She focuse on identifying and quantifying the pathogenic bacteria by POCT methods, and her e-mail address is 2937558984@qq.com.

\section{References}

1. Wu XX, Chen YX, Fan QQ. Evaluation of immune function in neonates with infectious pneumonia and its clinical significance [J]. Chinese Journal of experimental and clinical infectious diseases, 2019, 13(2): 128-133.

2. Zhu T, Lu QB, Zhang SY, et al. Molecular epidemiology of WU polyomavirus in hospitalized children with acute respiratory tract infection in China[J]. Future microbiology, 2017, 12(6): 481-489.

3. Soudani N, Caniza MA, Assaf-Casals A, et al. Prevalence and characteristics of acute respiratory virus infections in pediatric cancer patients[J]. Journal of Medical Virology, 2019, 91(7): 1191-1201. 
4. van der Galiën HT, Loeffen EAH, Miedema KGE,et al. Predictive value of PCT and IL-6 for bacterial infection in children with cancer and febrile neutropenia[J]. Supportive care in cancer: official journal of the Multinational Association of Supportive Care in Cancer, 2018, 26(11): 3819-3826.

5. Feng M, Zhang SL, Liang ZJ, et al. Peripheral neutrophil CD64 index combined with complement, CRP, WBC count and B cells improves the ability of diagnosing bacterial infection in SLE[J]. Lupus. 2019, 28(3): 304-316.

6. Tang JH, Gao DP, Zou PF. Comparison of serum PCT and CRP levels in patients infected by different pathogenic microorganisms: a systematic review and meta-analysis[J]. Braz J Med Biol Res. 2018, 51(7): 1-8.

7. Meili M, Kutz A, Briel M, et al. Infection biomarkers in primary care patients with acute respiratory tract infections-comparison of Procalcitonin and C-reactive protein[J]. BMC Pulm Med, 2016, 16(1): 43-50.

8. Giannini O, Giorno R D, Zasa A, et al. Comparative Impact of C-Reactive Protein Testing in Hospitalized Patients with Acute Respiratory Tract Infection: A Retrospective Cohort Study[J]. Advances in Therapy, 2019, 36(11): 3186-3195.

9. Hu YM, Jang ZF, Zhu FT. Applied Pediatrics[M].7th Edition. Beijing: People's Health Publishing House, 2002: 1163-1199.

10. Kikkert M. Innate immune evasion by human respiratory RNA viruses[J]. Journal of innate immunity, 2020, 12(1): 4-20.

11. Fuchs A, Gotta V, Decker ML, et al. Cytokine kinetic profiles in children with acute lower respiratory tract infection: a post hoc descriptive analysis from a randomized control trial[J]. Clin Microbiol Infect. 2018, 24(12): 1341.e1-1341.e7.

12. Crouser ED, Parrillo JE, Seymour C, et al. Improved Early Detection of Sepsis in the ED With a Novel Monocyte Distribution Width Biomarker[J]. Chest. 2017, 152(3): 518-526.

13. Walsh TL, DiSilvio BE, Hammer C. et al. Impact of Procalcitonin Guidance with an Educational Program on Management of Adults Hospitalized with Pneumonia[J]. Am. J. Med. 2018,131(2): 201.e1-201.e8.

14. Memar MY, Varshochi M, Shokouhi B, et al. Procalcitonin: The marker of pediatric bacterial infection[J]. Biomedicine \& pharmacotherapy = Biomedecine \& pharmacotherapie, 2017, 96(2017):936-943.

15. Zhang P, Xia G, Dai L, et al. Laryngoscope-assisted and cotton ball wiping methods in prevention of oral and pulmonary infection in patients receiving mechanical ventilation and the influence on hypersensitive C-reactive protein and procalcitonin[J]. Exp Ther Med, 2019, 18(1): 531-536.

16. Venge P, Eriksson S, Pauksen K. Blood biomarker algorithms for the diagnosis of mycoplasma pneumoniae respiratory infections[J]. Journal of Immunological Methods, 2021, 489-504

17. Bartoletti M, Antonelli M, Bruno Blasi FA, et al. Procalcitonin-guided antibiotic therapy: an expert consensus[J]. Clin Chem Lab Med. 2018, 56(8): 1223-1229. 
18. Wang Z, Huo B, Wu Q, et al. The role of procalcitonin in differential diagnosis between acute radiation pneumonitis and bacterial pneumonia in lung cancer patients receiving thoracic radiotherapy[J]. Sci Rep. 2020, 10(1): 2941-2946.

19. Kaur K, Mahajan R, Tanwar A. A novel marker procalcitonin may help stem the antibiotic overuse in emergency setting[J]. Int J Appl Basic Med Res, 2013, 3(2): 77-83.

20. Shen W, Lai S. Diagnostic Value of SCD163 Combined with PCT and HS-CRP in Patients with Gynecological Malignant Tumors and Fever[J]. J Coll Physicians Surg Pak. 2020, 30(10): 10531057.

21. Fouad NA, Fouad MA, Assar EH, et al. Combination of Procalcitonin, CRP and CD11b Biomarkers in Early Detection of Neonatal Sepsis[J]. Egypt J Immunol. 2020, 27(1): 77-86.

22. Yang AP, Liu J, Yue LH, et al. Neutrophil CD64 combined with PCT, CRP and WBC improves the sensitivity for the early diagnosis of neonatal sepsis[J]. Clin Chem Lab Med. 2016, 54(2): 345-351.

23. Zheng N, Zhu D, Han Y. Procalcitonin and C-reactive protein perform better than the neutrophil/lymphocyte count ratio in evaluating hospital acquired pneumonia[J]. BMC Pulm Med. 2020, 20(1): 166-176.

\section{Figures}

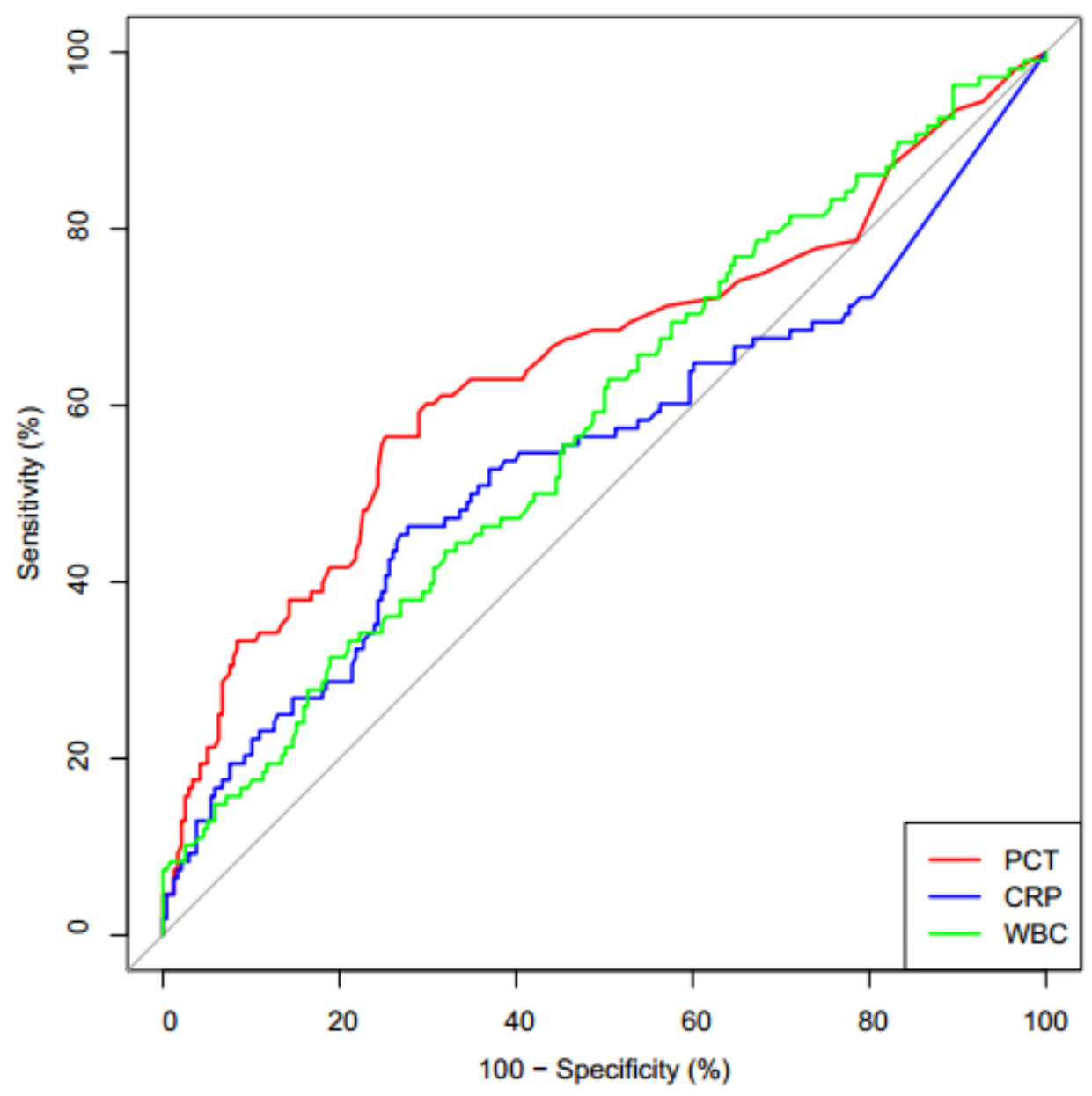


Figure 1

ROC curve of PCT, CRP and WBC in diagnosis of bacterial ARTI 